\title{
Gynecologic Surgery in the Geriatric Patient
}

\author{
Elisabeth A. Erekson, MD MPH [assistant professor], Elena S. Ratner, MD [assistant \\ professor], Lisa M. Walke, MD [associate professor], and Terri R. Fried, MD [professor] \\ Section of Urogynecology and Reconstructive Pelvic Surgery at Yale University School of \\ Medicine, New Haven, Connecticut; the Section of Gynecologic Oncology at Yale University \\ School of Medicine, and the Section of Geriatrics at Yale University School of Medicine, New \\ Haven, Connecticut
}

\section{Case}

A multiparous woman in her mid-80s presented with complete uterine procidentia and difficulty with urination to a tertiary care center for surgery. She denied urinary incontinence. She lived by herself and walked with a cane. She had a past medical history significant for hypertension, osteoporosis with vertebral fracture, and hypercholesterolemia. She had no history of acute myocardial infarction, cerebral vascular accident, or malignancy. Medications included a beta blocker, a thiazide diuretic, an HMG-CoA reductase inhibitor, and a bisphosphonate. She denied taking vitamins or herbal medications.

Physical examination revealed complete uterine procidentia with vaginal atrophy but no ulcerations. Simple uroflow demonstrated an interrupted voiding pattern. No urine leakage was seen with stress maneuvers with a full bladder with the prolapse reduced. Papanicolaou test and endometrial biopsy were negative for malignancy. The patient elected to proceed with an obliterative procedure to correct her pelvic organ prolapse. Preoperatively, her serum sodium, serum creatinine, and estimated glomerular filtration rate were $132 \mathrm{mEq} / \mathrm{L}$, $0.8 \mathrm{mg} / \mathrm{dL}$ and $>60 \mathrm{~mL} /$ minute, respectively. Beyond noting her living arrangements, history of falls, and walking with assistance, her functional and cognitive status was not formally assessed preoperatively.

The patient underwent an uncomplicated modified LeFort colpocleisis, perineorrhaphy, and cystoscopy under general endotracheal anesthesia. Regional anesthesia was not chosen due to her vertebral fracture. Total anesthesia time was 106 minutes and estimated blood loss was $50 \mathrm{~mL}$. On the morning of postoperative day \#1, she ambulated to the bathroom, tolerated a regular diet, and reported adequate pain control. Physical therapy, consulted to evaluate her balance and gait, recommended a rolling walker to use with ambulation. She could stand independently and navigate 5 stairs without assistance. Her serum sodium was $130 \mathrm{mEq} / \mathrm{L}$. The patient was discharged home on postoperative day \#1.

On postoperative day \#5, the patient fell in her home and was found by her daughter on the floor approximately 30 minutes later. She had used no narcotic pain medication since her surgery. She was re-admitted to the hospital for dehydration and hyponatremia (serum sodium $127 \mathrm{mEq} / \mathrm{L}$ ) which was believed to have been the cause of her fall. Fortunately, no fracture was observed. She moved to her daughter's house. She continued to be

(C2010 American Medical Association. All rights reserved.

Corresponding Author: Elisabeth A. EREKSON, MD MPH, Yale University, Section of Urogynecology, 333 Cedar St, PO Box 208063, New Haven, CT 06519-8063, (203) 785-6927, Fax (203) 785-2909 elisabeth.erekson@ yale.edu.

Financial Disclosure: The authors did not report any potential conflicts of interest. 
hyponatremic despite discontinuation of thiazide diuretic. Eighteen months following surgery she reported having regained her strength and energy level. She experienced one additional fall with no major injury.

\section{Key Questions}

How common is gynecologic surgery in women 65 years and older in the U.S? What are the indications for these gynecologic procedures?

In the United States, 237,000 gynecologic procedures, mostly hysterectomy, oophorectomy, or hysterectomy and oophorectomy, are performed annually in women aged 65 years and over for an age-adjusted surgical rate of 63.8 gynecologic procedures per 10,000 women aged 65 years and over.(1) As women age, uterine leiomyoma and endometriosis decline as indications for surgery in postmenopausal women while uterine prolapse and gynecologic malignancies persist. (2) The U.S Census bureau has predicted that the population of adults over the age of 65 will increase from 46,059,000 in 2010 to 108,189,000 in 2050.

Additionally, the age structure among adults over 65 years old is predicted to shift with the largest proportion of this older population shifting from the 65 to 69 year old age group in 2010 to the 80 to 84 year old age group in 2050 . Therefore, the number of older women in need of gynecologic surgical procedures will rise in the upcoming decades.

\section{What complications are common in older women undergoing surgical procedures?}

Four common postoperative complications among older women are falls, delirium, surgical site infections, and electrolyte imbalance.(3)

Falls-Falls are common. Thirty percent of community dwelling adults over 65 years old fall every year and $10 \%$ of these falls result in a major injury including fracture, serious soft tissue injury, or traumatic brain injury.(4) Another serious consequence is the inability to get up after a fall which can result in significant morbidity including dehydration, pressure ulcers, and rhabdomyolysis. Risk factors predisposing older adults to falls include previous falls, balance impairment, gait disturbances, decreased muscle strength, visual impairments (including cataracts), polypharmacy ( $>4$ medications), functional impairment of activities of daily living, depression, low body mass index, age $>80$ years, female gender, and cognitive impairments.(4)

Delirium-Delirium is an acute state of confusion and is a common complication reported in $17 \%$ of older women undergoing procedures for gynecologic cancer. Delirium is often unrecognized, so the true occurrence of postoperative delirium may be higher. Postoperative delirium is common in older patients and associated with increased mortality, longer hospital stays, and increased discharge to skilled nursing facilities. Unfortunately, 50 to $80 \%$ of acute episodes of delirium in hospitalized patients are unrecognized. The Confusion Assessment Method diagnostic algorithm is an easy assessment tool for identifying delirium. $(5,6)($ Box 1$)$

Surgical site infections-Surgical site infections. Increase with increasing age. Impaired functional status for activities of daily living (ADLs) is an important independent predictor of surgical site infection, especially methicillin-resistant Staphylococci infections, even after stratifying patients by age. $(3,7)$

Electrolyte imbalance-Electrolyte imbalance is common in older patients. With aging, glomerular filtration rate, sodium reabsorption and potassium secretion decrease, resulting in diminished renal reserve and electrolyte imbalances.(8) (9) Perioperative fluid management in older patients should be carefully monitored to avoid either fluid overload or dehydration. 


\section{Can postoperative falls be predicted or prevented?}

A review of a woman's personal risk factors and mobility screening can identify patients at risk of fall. A simple screening test for mobility is the Get up and Go test. Patients are asked to get up from a chair without using the armrests, walk 10 feet, turn and return to the chair and sit down. A total "Get up and Go" test time of less than 12 seconds indicates normal mobility. Patients should be referred for a more comprehensive mobility assessment if the time exceeds 12 seconds or if balance or gait challenges are observed.

Interventions studied to reduce falls include home safety modifications, medication reduction, physical therapy, exercise, and vision improvements. Although some single intervention and multiple intervention trials were shown to be ineffective, most of the effective trials for the prevention of falls include a tailored combined intervention that addresses an individual's specific risk factors for falls. (Table 1) : for example, cataract surgery to improve vision or comprehensive medication review to reduce polypharmacy. Women with balance or gait impairments benefit from physical or occupation therapy for progressive strength, balance and gait training. Home visits are helpful to implement adaptive devices (grab bars, raised toilet seats, and shower chairs), remove tripping hazards such as throw rugs, ensure adequate lighting (nightlights for women with nocturia), place an accessible telephone on the floor level, and enroll women in emergency response systems for help if they do experience a fall. Two types of emergency response systems exist. One system triggers an automatic call if the patient falls. The other system needs to be triggered by the patient. Both have been shown beneficial in patients with a history of falls.

Attempting to avoid all inpatient falls, through prolonged bedrest and mobility only with strict supervision may result in decreased mobility, decreased strength, unnecessary restrictions on patient autonomy and decreased patient dignity. A balanced approach to fall prevention that encourages mobility is important in hospitalized patients.

\section{Can postoperative delirium be predicted or prevented?}

Risk factors included in one clinical prediction model for postoperative delirium after noncardiac surgery include: age $\geq 70$ years, alcohol abuse, preoperative cognitive impairment, preoperative physical impairment, and abnormal serum sodium ( $<130$ or $>150 \mathrm{mmol} / \mathrm{L})$, potassium $(<3.0$ or $>16.7 \mathrm{mmol} / \mathrm{L})$, or glucose $(<60$ or $>300 \mathrm{mg} / \mathrm{dL}) .(10)$ In a study of women $>60$ years undergoing surgery for suspected gynecologic malignancy, age $>70$ years, taking $>5$ medications, and additional narcotic dosing to supplement intravenous patient-controlled analgesia independently predicted postoperative delirium.(11) Postoperative delirium increases with increasing risk factors as well as the degree of stress or insult sustained. Because delirium is relatively common in elderly postoperative patients and prevention and treatment decrease morbidity, we assess all elderly women daily by noting if patients are easily distracted, disoriented, or have disorganized thinking or altered levels of consciousness (hyperalert or lethargic).(12) We liberally consult geriatric colleagues if signs of delirium are recognized.

Multi-component interventions to reduce delirium are aimed at recognizing its risk factors: cognitive impairment, sleep deprivation, immobility, visual impairment, hearing impairment, and dehydration. Interventions reduce both the occurrence of delirium in hospitalized patients and the duration of the delirium.(13) To support the delirious patient: 1) provide easy to read clocks and calendars to allow patients to maintain orientation, 2) encourage frequent introductions and cognitive reorientation by staff, 3) encourage a normal sleep-wake cycle by reducing auditory alarms, 4) avoide routine vital signs collection and medication administration during sleep, 5) minimize indwelling catheters and other lines or "tethers" so the patient can move freely, 6) eliminate physical restraints as soon as possible, 
7) optimize sensory input by ensuring correct usage of glasses and hearing aids, 8) monitor urine and stool output to prevent retention or impaction, and 9) support meals assistance of cutting food and hand-feeding if necessary. Specialized units, termed acute care of the elderly (ACE) units, have been implemented at hospitals to prevent delirium and provide supportive care to patients who develop delirium.

\section{What can be done in the preoperative period to decrease the risk of postoperative complications in older woman planning gynecologic surgery?}

Preoperative medical risk assessments should include a comprehensive cardiac and pulmonary history with an evaluation of clinical predictors of perioperative cardiac events, including ischemic heart disease, congestive heart failure, documented cerebrovascular disease, insulin-dependent diabetes mellitus, and/or serum creatinine > 2.0mg/dl.(14) Using the algorithm outlined by the American College of Cardiology and the American Heart Association can help to identify patients who will benefit from preoperative cardiac testing (stress test or coronary angiography) or perioperative medical therapy with beta-blockers. (15) In women undergoing intermediate risk surgery (laparotomy) with one or more of the above clinical risk factors for perioperative cardiac events abeta-blocker should be started pre-operatively. The exact timing of initiation and duration of therapy is still under debate. Review all medications a patient is taking including alternative and herbal medications to identify which medications should be continued through the operative period. For medications that will be stopped in the operative period, clearly communicate the timing of discontinuation and reinstitution.

Preoperative smoking cessation counseling represents a unique opportunity to motivate change that can also decrease postoperative complications. Intensive interventions to promote smoking cessation with counseling sessions and nicotine replacement treatment for at least 4 to 8 weeks before surgery result in sustained abstinence after surgery and fewer postoperative complications. $(16,17)$ When smoking cessation is initiated within 4 weeks of surgery, postoperative complications are generally not reduced. It is thought that smoking can result in small impairments of the immune system that may take prolonged abstinence to recovery. It is also important to elicit preoperative alcohol intake. The four T-ACE

(Tolerance, Annoyed, Cut down, and Eye-opener) questions are helpful in screening women for at-risk drinking.(18) Patients identified for at-risk drinking can be offered referral for substance abuse care and treated for symptoms of alcohol withdrawal while inpatient after surgery.

Another important intervention is preoperative exercise training or "prehabilitation".(19) Preoperative physical activity, either respiratory muscle training or aerobic activity over 3 weeks to 6 months, can decrease postoperative complications. Respiratory muscle training (deep breathing with a progressive increase in rate of perceived exertion) for 2 weeks before cardiac or major vascular surgery may improve some pulmonary outcomes . Similarly, preoperative aerobic activity or simple walking programs can improve walking capacity in patients. The indications for surgery may dictate the amount of time between deciding on surgery and when the surgery can be performed. Procedures for gynecologic cancer may need to be performed within weeks of diagnosis which may preclude "prehabiltation". In contrast, procedures for pelvic floor disorders are often elective and may present a unique opportunity for these health interventions.

\section{Why are markers of frailty and functional status important to measure in the preoperative medical risk assessment?}

Frailty is a common biologic syndrome of decreased reserve and resistance to stressors that increases with age. Easily measured markers of frailty include slow gait speed, low physical 
activity, unintentional weight loss, self-reported exhaustion, muscle weakness, cognitive impairment and depression. Frailty can be measured before overt functional disability is recognized by healthcare professionals or acknowledged by older adults. Frailty is an intermediate step predictive of morbidity before overt functional disability is evident.

Postoperative complications are increased in women with frailty and overt functional disability for activities of daily living. (7, 20-22), suggesting that frailty and functional status should be considered, in addition to age and medical comorbidities, in preoperative medical risk assessments.

Malani et al has advocated for routinely assessing mobility, cognition and function in older adults before elective surgery pre-operatively.(3) Assessment tools include the Get Up and Go test for mobility, the Mini-Cog screen for cognitive impairment (Box 2), and a review of the functional and instrumental ADLs. The Mini-Cog screen is a simple screening test for cognitive impairment that asks a patient to remember three words and then draw a clock face correctly. Examples of errors in clock drawing are illustrated in Figure 1. Functional ADLs include walking one block, walking across a room, putting on shoes and socks, bathing or showering, cutting food, getting in and out of bed, and using the toilet. Instrumental ADLs include ability to perform tasks such as balancing a checkbook, paying bills, and grocery shopping. Often, deficiencies in mobility and mild cognition impairment are present before overt functional disability is present.

In our practice, we have added measures of frailty and functional status in women over 80 years prior to gynecologic surgery to complement the preoperative medical risk assessments. (Table 2) This added evaluation takes between 5 and 10 minutes. While we chose to do this added evaluation, which takes between 5 and 10 minutes in women over 80 because of the clear increase in complication risk over this cut-point, further research is needed to merge aging related research with outcomes research in gynecology to provide more specific data on complications in women over 65 years, 80 years, and beyond.

\section{References}

1. National Center for Health Statistics. 2006 national hospital discharge survey [Internet]. Centers for Disease Control. 2008. [updated 07/30/2008. Available from: http://www.cdc.gov/nchs/data/nhsr/ nhsr005.pdf

2. Whiteman M, Hillis S, Jamieson D, Morrow B, Podgornik M, Brett K, et al. Inpatient hysterectomy surveillance in the united states, 2000-2004. Obstet Gynecol. 2008; 198(1):34-e1. 34-e7.

3. Malani P. Functional status assessment in the preoperative evaluation of older adults. JAMA. 2009; 302(14):1582. [PubMed: 19826029]

4. Tinetti, M.; Kumar, C. JAMA. Vol. 303. Chicago, Ill: 2010. The patient who falls: "it's always a trade-off"; p. 258-66.

5. Inouye SK, van Dyck CH, Alessi CA, Balkin S, Siegal AP, Horwitz RI. Clarifying confusion: The confusion assessment method. A new method for detection of delirium. Ann Intern Med. 1990; 113(12):941-8. [PubMed: 2240918]

6. Inouye S. Delirium in older persons. N Engl J Med. 2006; 354(11):1157-65. [PubMed: 16540616]

7. Chen T, Anderson D, Chopra T, Choi Y, Schmader K, Kaye K. Poor functional status is an independent predictor of surgical site infections due to methicillin-resistant staphylococcus aureus in older adults. J Am Geriatr Soc. 2010; 58(3):527-32. [PubMed: 20158557]

8. Musso C, Oreopoulos D. Aging and physiological changes of the kidneys including changes in glomerular filtration rate. Nephron Physiology. 2011; 119(1):1-5.

9. Beck LH. Perioperative renal, fluid, and electrolyte management. Clin Geriatr Med. 1990; 6(3):55769. [PubMed: 2199019] 
10. Marcantonio, ER.; Goldman, L.; Mangione, CM.; Ludwig, LE.; Muraca, B.; Haslauer, CM., et al. JAMA. Vol. 271. Chicago, Ill: 1994. A clinical prediction rule for delirium after elective noncardiac surgery; p. 134-9.

11. McAlpine JN, Hodgson EJ, Abramowitz S, Richman SM, Su Y, Kelly MG, et al. The incidence and risk factors associated with postoperative delirium in geriatric patients undergoing surgery for suspected gynecologic malignancies. Gynecol Oncol. 2008; 109(2):296-302. [PubMed: 18374970]

12. Flinn D, Diehl K, Seyfried L, Malani P. Prevention, diagnosis, and management of postoperative delirium in older adults. J Am Coll Surg. 2009; 209(2):261-8. [PubMed: 19632604]

13. Inouye SK, Bogardus ST, Charpentier PA, Leo Summers L, Acampora D, Holford TR, et al. A multicomponent intervention to prevent delirium in hospitalized older patients. N Engl J Med. 1999; 340(9):669-76. [PubMed: 10053175]

14. Eagle K, Berger P, Calkins H, Chaitman B, Ewy G, Fleischmann K, et al. ACC/AHA guideline update for perioperative cardiovascular evaluation for noncardiac surgery--executive summary: A report of the american college of Cardiology/American heart association task force on practice guidelines (committee to update the 1996 guidelines on perioperative cardiovascular evaluation for noncardiac surgery). J Am Coll Cardiol. 2002; 39(3):542-53. [PubMed: 11823097]

15. Fleischmann K, Beckman J, Buller C, Calkins H, Fleisher L, Freeman W, et al. 2009 ACCF/AHA focused update on perioperative beta blockade. J Am Coll Cardiol. 2009; 54(22):2102-28. [PubMed: 19926021]

16. Lindstrm D, Sadr Azodi O, Wladis A, Tnnesen H, Linder S, Nsell H, et al. Effects of a perioperative smoking cessation intervention on postoperative complications: A randomized trial. Ann Surg. 2008; 248(5):739-45. [PubMed: 18948800]

17. Thomsen T, Villebro N, Mller A. Interventions for preoperative smoking cessation. Cochrane database of systematic reviews. 2010; (7):CD002294.

18. Sokol RJ, Martier SS, Ager JW. The T-ACE questions: Practical prenatal detection of riskdrinking. Obstet Gynecol. 1989; 160(4):863-8.

19. Jack S, West M, Grocott MPW. Perioperative exercise training in elderly subjects. Bailliere's best practice research. Clinical anaesthesiology. 2011; 25(3):461-72. [PubMed: 21925410]

20. Hamel M, Henderson W, Khuri S, Daley J. Surgical outcomes for patients aged 80 and older: Morbidity and mortality from major noncardiac surgery. J Am Geriatr Soc. 2005; 53(3):424. [PubMed: 15743284]

21. Makary M, Segev D, Pronovost P, Syin D, Bandeen-Roche K, Patel P, et al. Frailty as a predictor of surgical outcomes in older patients. J Am Coll Surg. 2010; 210(6):901-8. [PubMed: 20510798]

22. Lee D, Buth K, Martin B, Yip A, Hirsch G. Frail patients are at increased risk for mortality and prolonged institutional care after cardiac surgery. Circulation. 2010 


\section{Box 1: Algorithm for the Diagnosis of Delirium}

Feature 1. Acute change in mental status and fluctuating course

- Is there evidence of an acute change in cognition from baseline?

- Does the abnormal behavior fluctuate during the day?

Feature 2. Inattention

- Does the patient have difficulty focusing attention (eg, easily distracted, has difficulty keeping track of what is being said)?

Feature 3. Disorganized thinking

- Does the patient have rambling or irrelevant conversations, unclear or illogical flow of ideas, or unpredictable switching from subject to subject?

Feature 4. Abnormal level of consciousness

- Is the patient anything besides alert - hyperalert, lethargic, stuporous, or comatose?

The diagnosis of delirium requires features 1 and 2 plus either 3 or 4 .

Modified from Inouye SK, van Dyck CH, Alessi CA, Balkin S, Siegal AP, Horwitz RI. Clarifying confusion: the confusion assessment method. A new method for detection of delirium. Ann Intern Med 1990;113:941-8. 


\section{Box 2. Mini-Cog Screen for Dementia}

The Mini-Cog combines an uncued three-item recall test with a clock-drawing test that serves as the recall distractor. The Mini-Cog can be administered in about 3 minutes, requires no special equipment, and is less influenced by level of education or language differences.

\section{Administration}

1. Make sure you have the patient's attention. Then instruct the patient to listen carefully to, repeat back to you, and remember (now and later) three unrelated words. You may present the same words up to three times if necessary.

2. Instruct the patient to draw the face of a clock, either on a blank sheet of paper, or on a sheet with the clock circle already drawn on the page. After the patient puts the numbers on the clock face, ask him or her to draw the hands to read a specific time (11:10 or 8:20 are most commonly used; however, other times that require use of both halves of the face may be effective). These instructions can be repeated, but no additional instructions should be given. If the patient cannot complete the clock-drawing test in 3 minutes or less, move on to the next step.

3. Ask the patient to repeat the three previously presented words.

Scoring

1. Give 1 point for each recalled word after the clock-drawing test distractor. Score 0-3 for recall.

2. Give 2 points for a normal clock-drawing test, and 0 points for an abnormal clock-drawing test. The clock-drawing test is considered normal if all numbers are depicted, once each, in the correct sequence and position around the circle, and the hands readably display the requested time. Do not count equal hand lengths as an error. Add the recall and clock-drawing test scores together to get the Mini-Cog score:

- $0-2$ positive screen for dementia

- 3-5 negative for dementia

Modified from Borson et al. Reprinted with permission of S. Borson. Mini-Cog Copyright 2000, 2006, 2007. All rights reserved. Licensed for reprint distribution by S. Borson, MD, solely for use as a clinical aid. Any other use is strictly prohibited. To obtain information on the Mini-Cog, contact Dr. Borson at soob@u.washington.edu. 

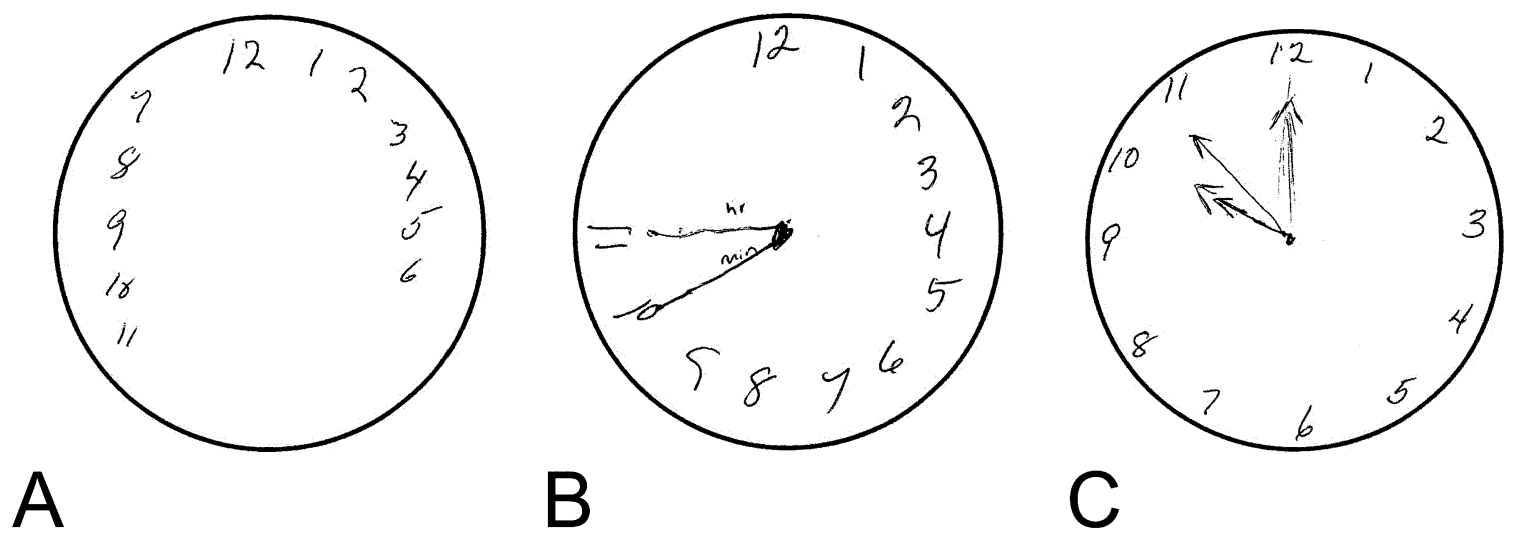

Figure 1.

Examples of clock-drawing errors. Elderly women were asked to draw a clock face (circle was provided) and the hands at "ten minutes to eleven." A. incorrect number sequence and missing hands. B. poor planning resulting in gross error of number spacing. C. more than 2 hands and incorrect time. 
Table 1

Recommended Assessment and Management of Predisposing and Precipitating Factors for Falls Among Community-Living Older Adults Based on Observational and Trial Evidence

\begin{tabular}{|c|c|c|c|}
\hline & Level of Evidence* & Screen and Assessment & Management \\
\hline \multicolumn{4}{|l|}{ Predisposing factors } \\
\hline $\begin{array}{l}\text { Cardiovascular (carotid } \\
\text { sinus hypersensitivity, } \\
\text { bradyarrhythmias, } \\
\text { tachyarrhythmias) }\end{array}$ & $\mathrm{Ib}$ & $\begin{array}{l}\text { Cardiac evaluation, including heart rate } \\
\text { and blood pressure responses to carotid } \\
\text { sinus stimulation if indicated }\end{array}$ & $\begin{array}{l}\text { Medication management as indicated; } \\
\text { consider dual chamber cardiac pacing }\end{array}$ \\
\hline Postural hypotension & Ia & $\begin{array}{l}\text { Check blood pressure and pulse after } \\
\text { more than } 5 \text { min supine, then on standing. }\end{array}$ & $\begin{array}{l}\text { Reduce or eliminate medications likely to } \\
\text { contribute (eg, antihypertensive } \\
\text { medications, alpha agonists, tricyclic } \\
\text { antidepressants); dorsiflexion and hand } \\
\text { clench exercises before arising; } \\
\text { compression stockings; }\end{array}$ \\
\hline $\begin{array}{l}\text { Other chronic conditions } \\
\text { (especially arthritis, } \\
\text { neurological diseases) }\end{array}$ & III & $\begin{array}{l}\text { Musculoskeletal and neurological } \\
\text { examination }\end{array}$ & $\begin{array}{l}\text { Treat the underlying disease(s) and } \\
\text { manage the identified musculoskeletal } \\
\text { and neurological impairments }\end{array}$ \\
\hline $\begin{array}{l}\text { Cognitive impairment or } \\
\text { dementia }\end{array}$ & III & Mini-Cog test & \\
\hline Balance or gait impairment & Ia & Get Up and Go test & $\begin{array}{l}\text { Refer to physical or occupational therapy } \\
\text { for progressive strength, balance, and gai } \\
\text { training; appropriate assistance device }\end{array}$ \\
\hline \multirow[t]{2}{*}{ Vision problems } & $\mathrm{Ib}$ & Check for cataracts & Refer for single cataract extraction \\
\hline & III & $\begin{array}{l}\text { Check visual acuity (eg, Snellen and } \\
\text { Jaeger charts; have patient read headline } \\
\text { and sentence from a newspaper }\end{array}$ & $\begin{array}{l}\text { Refer to low vision clinic if severe } \\
\text { impairment interferes with mobility or } \\
\text { functioning }\end{array}$ \\
\hline $\begin{array}{l}\text { Psychoactive and other } \\
\text { medications }\end{array}$ & Ia & $\begin{array}{l}\text { Medication review, including both } \\
\text { prescription and nonprescription } \\
\text { medications, especially if taking four or } \\
\text { more or a high-risk medication; because } \\
\text { patients are unlikely to volunteer such } \\
\text { information, clinicians also should } \\
\text { inquire about common medication-related } \\
\text { adverse effects such as confusion, } \\
\text { impaired alertness, fatigue, insomnia, } \\
\text { dizziness, unsteadiness, or decreased } \\
\text { appetite }\end{array}$ & $\begin{array}{l}\text { Eliminate or reduce dose of as many of } \\
\text { the following as possible: sedatives, } \\
\text { antidepressants, anxiolytics, } \\
\text { antipsychotics, and medications that } \\
\text { cause (1) orthostasis (eg, } \\
\text { antihypertensives, alpha blockers, } \\
\text { nitrates); (2) confusion or impaired } \\
\text { alertness (eg, antihistamines, } \\
\text { anticonvulsants); (3) parkinsonism; or (4) } \\
\text { other (eg, digitalis) }\end{array}$ \\
\hline $\begin{array}{l}\text { Functional disabilities } \\
\text { (activities of daily living } \\
\text { limitations) }\end{array}$ & Ia & Assessment tools & $\begin{array}{l}\text { Physical and occupational therapy; home } \\
\text { safety modifications }\end{array}$ \\
\hline \multicolumn{4}{|l|}{ Precipitating factors } \\
\hline Home hazards & Ia & $\begin{array}{l}\text { Home visit (by occupational therapist, } \\
\text { physical therapist, nurse); self- } \\
\text { administered checklist }\end{array}$ & $\begin{array}{l}\text { Physical, occupational, or physical and } \\
\text { occupational therapy: adaptive devices } \\
\text { (eg, reaching device; sock aid and long } \\
\text { shoe horn; grab bars in the bathtub; } \\
\text { shower chair; raised toilet seats). Remove } \\
\text { tripping hazards; ensure adequate } \\
\text { lighting; other safety measures (eg, keep } \\
\text { a cell phone in pocket at all times; enroll } \\
\text { in personal emergency response system) }\end{array}$ \\
\hline
\end{tabular}




\begin{tabular}{llll}
\hline & Level of Evidence & Screen and Assessment & Management \\
\hline $\begin{array}{l}\text { Footwear and foot } \\
\text { problems }\end{array}$ & III & $\begin{array}{l}\text { Ask about foot pain; check for bunions, } \\
\text { toe deformities, and peripheral } \\
\text { neuropathy }\end{array}$ & Refer to podiatrist \\
\hline III & Check footwear & $\begin{array}{l}\text { Advise patients that walking with well- } \\
\text { fitting shoes of low heel height and high } \\
\text { surface contact area may reduce falls }\end{array}$ \\
\hline $\begin{array}{l}\text { Multifocal eyeglasses } \\
\text { Now eyeglass prescription }\end{array}$ & II & Ib & $\begin{array}{l}\text { Avoid multifocal lenses while walking, } \\
\text { especially on stairs }\end{array}$ \\
\hline Alcohol & IV & $\begin{array}{l}\text { Caution that there may be an increased } \\
\text { risk of falling after new lenses are placed }\end{array}$ \\
\hline
\end{tabular}

The CAGE questionnaire $(\mathrm{C}=$ cut down, $\mathrm{A}=$ annoyed, $\mathrm{G}=$ guilt, $\mathrm{E}=$ eye opener $)$ is a short, four-question test that diagnoses alcohol problems over a lifetime.

* Level of evidence based on the results of authors' three systematic reviews: class Ia, evidence from at least two randomized controlled trials; Ib, evidence from one randomized controlled trial or meta-analysis of randomized controlled trials; II, evidence from at least one nonrandomized controlled trial or quasi-experimental study; III, evidence from prospective cohort study (risk factor for falls); IV, based on expert committee opinion or clinical experience in absence of other evidence. All management recommendations also meet the criteria of ease of implementation and clinical importance.

Modified from Tinetti ME, Kumar C. The patient who falls: "It's always a trade-off.” JAMA. 2010;303:258-266. @2010 American Medical Association. All rights reserved. 
Table 2

Recommendations for Preoperative Medical Risk Assessment for Women Aged Older Than 80 Years Undergoing Gynecologic Surgery

\begin{tabular}{|c|c|}
\hline Assessment & Intervention \\
\hline $\begin{array}{l}\text { Mobility assessment } \\
\text { Does the patient have a history of falling? } \\
\text { Get up and Go test-normal mobility time is fewer } \\
\text { than } 12 \text { seconds } \\
\text { - } \quad \text { get up from a chair without using the armrests } \\
\text { - } \quad \text { walk } 10 \text { feet } \\
\text { - turn around } \\
\text { - } \quad \text { return } 10 \text { feet to the chair } \\
\text { - sit down }\end{array}$ & $\begin{array}{l}\text { Consider physical therapy and occupational therapy evaluation in hospital } \\
\text { Consider home health evaluation } \\
\text { Treat underlying causes of falls }\end{array}$ \\
\hline Cognitive status testing Mini-Cog & $\begin{array}{l}\text { Delirium screening in hospitalProvide supportive care if delirious: } \\
\text { - } \quad \text { Easy-to-read clocks and calendars for orientation } \\
\text { - } \quad \text { Encquent introductions/reorientations by staff } \\
\text { - } \quad \begin{array}{l}\text { Minimize or eliminate indwelling catheters, extraneous lines, and } \\
\text { restraints }\end{array} \\
\text { - } \quad \text { Encourage use of vision and hearing aids for sensory input } \\
\text { - } \quad \text { Ponitor urine and stool output to prevent retention }\end{array}$ \\
\hline $\begin{array}{l}\text { Functional status } \\
\text { Review difficulty or dependence on others for } \\
\text { activities of daily living } \\
\text { - } \quad \text { walking one block } \\
\text { - } \quad \text { walking across a room } \\
\text { - } \quad \text { putting on shoes and socks } \\
\text { - } \quad \text { bathing or showering } \\
\text { - } \quad \text { cutting your food } \\
\text { - } \quad \text { getting in and out of bed } \\
\text { - } \quad \text { using the toilet }\end{array}$ & $\begin{array}{l}\text { Consider home health evaluation } \\
\text { - } \quad \text { implementing the use of adaptive devices(grab bars, raised toilet } \\
\text { seats, and shower chairs) } \\
\text { - } \quad \text { removing tripping hazards such as throw rugs } \\
\text { - } \quad \text { ensuring adequate lighting (nightlights) } \\
\text { - } \text { placing an accessible telephone on the floor level } \\
\text { - } \quad \text { enrolling women in emergency response systems }\end{array}$ \\
\hline Comprehensive cardiac and pulmonary evaluation & $\begin{array}{l}\text { Identify women who will benefit from cardiac testing stress test or coronary } \\
\text { angiography Identify women who will benefit from perioperative beta-blockade }\end{array}$ \\
\hline Complete medication review & $\begin{array}{l}\text { Review all medications including vitamins and herbal supplements to determine } \\
\text { which medications should be continued or discontinued during the operative } \\
\text { period }\end{array}$ \\
\hline Tobacco history & $\begin{array}{l}\text { Smoking cessation counseling and nicotine replacement } 4 \text { to } 8 \text { weeks prior to } \\
\text { surgery }\end{array}$ \\
\hline Alcohol assessment & Utilize T-ACE questions to identify women with at risk drinking behaviors \\
\hline
\end{tabular}

T-ACE, $\mathrm{T}=$ tolerance, $\mathrm{A}=$ annoyed, $\mathrm{C}=$ cut down, $\mathrm{E}=$ eye-opener. 